\title{
Variability in pig skin gelatin properties related to production site: A near infrared and fluorescence spectroscopy study
}

\author{
Anne Duconseille a, Donato Andueza ${ }^{\text {b }}$, Fabienne Picard ${ }^{\text {b }}$, Véronique Santé-Lhoutellier ${ }^{\mathrm{a}}$, \\ Thierry Astruc ${ }^{\text {a, * }}$
}

a INRA Auvergne-Rhône-Alpes, Centre de Clermont-Ferrand-Theix, UR370 QuaPA, F-63122 Saint-Genès-Champanelle, France

b INRA, UMR Herbivores 1213, F-63122 Saint-Genes-Champanelle, France

\section{A R T I C L E I N F O}

\section{Article history:}

Received 15 April 2016

Received in revised form

13 July 2016

Accepted 1 August 2016

Available online 12 August 2016

\section{Keywords:}

Gelatin

Near infrared spectroscopy

Fluorescence spectroscopy

Dissolution quality

Production origin

\begin{abstract}
A B S T R A C T :
The pharmaceutical industry requires narrow variability in the dissolution rate of hard gelatin capsules. To test this property, gelatin is aged in high temperature and humidity conditions to mimic gelatin shelflife. These conditions induce cross-link formation in gelatin chains and change the properties of the capsule. Gelatin is produced worldwide in various environmental conditions. This study set out to evaluate the impact of geographic production origin on gelatin composition, before and after aging treatment, and on its dissolution properties. Non-aged and aged pig skin gelatins from three different production plants (A, B and C) were analyzed in raw granules and in powder by near infrared and fluorescence spectroscopy to identify the mechanisms of cross-link formation during aging. Gelatin composition (lipids, dityrosine, 3,4 dihydroxyphenylalanine (DOPA)) and oxidation level, before and after aging, varied according to production origin. The gelatin from $C$ showed no variability in dissolution rate, while gelatins from A and B dissolved more slowly after aging. Near infrared spectroscopy results suggest that water was more strongly bound to the gelatin chains in the gelatins that yielded non-compliant dissolution test results. Non-compliant gelatin exhibited more $\mathrm{CH}_{2}$, usually assigned to lipids, and more aldehydes. Even before aging we found that non-compliant gelatins tended to fluoresce more at $344 \mathrm{~nm}$ under $280 \mathrm{~nm}$ excitation. These results open new perspectives for designing tools to predict the dissolution quality of freshly produced gelatins.
\end{abstract}

(C) 2016 Elsevier Ltd. All rights reserved.

\section{Introduction}

Type A gelatin extracted from the extracellular matrix of pig skins results from collagen solubilization. This industrial process consists in grinding and pre-treating the pig skins in acidic conditions to extract the collagen. Generally, diluted sulfuric or hydrochloric acid $(2-4 \%)$ is used for up to $24 \mathrm{~h}$ at room temperature. During this pre-treatment, most of the fat floats to the surface, and so is easy to remove. The skins are then washed in water for $24 \mathrm{~h}$ to remove acid and salts, and immersed in a hot water bath with a temperature ranging from 50 to $100^{\circ} \mathrm{C}$ for $18-36 \mathrm{~h}$. In this step, the collagen is solubilized and extracted from the skins. The gelatin obtained is then filtered, demineralized, concentrated, sterilized, dried and ground into granules. During the extraction step, Maillard reactions can occur between the proteins and the traces of

\footnotetext{
* Corresponding author.

E-mail address: thierry.astruc@clermont.inra.fr (T. Astruc).
}

lipids, darkening the gelatin (Schrieber \& Gareis, 2007). Bleaching agents such as hydrogen peroxide can be added to lighten the color (Schrieber \& Gareis, 2007). The pharmaceutical industry uses gelatin to make hard capsules that must meet dissolution quality standards to release drugs homogeneously throughout their shelflife (United States Pharmacopeial Convention, 2012). Gelatin film dissolution in water is assessed by the increase of absorbance in the dissolution medium at $218 \mathrm{~nm}$. At least $50 \%$ of the gelatin has to dissolve in 9 min to meet the quality standard, throughout its lifetime. Gelatin dissolution is generally always good soon after it has been produced and variability in dissolution generally appears after aging (Duconseille, Andueza, Picard, Santé-Lhoutellier, \& Astruc, 2016). Thus prior to the dissolution test the gelatin is artificially aged. This aging step consists in exposing gelatins to high temperature and humidity conditions for several weeks.

One explanation for this variability that occurs mainly after gelatin aging could be an effect of the pig breed differences and to the making process which could influence cross-link formation 
between gelatin chains. Although not all the mechanisms of crosslink formation have been identified (Duconseille, Astruc, Quintana, Meersman, \& Sante-Lhoutellier, 2015), Maillard reactions are known to be responsible for the formation of some cross-links in high temperature and humidity conditions (Digenis, Gold, \& Shah, 1994).

Gelatin is produced worldwide at production sites with various climates (temperatures, humidity, etc.). The raw material (pig skins) is likely to differ in composition according to the country of production because of variability in genotypes, feeding and rearing conditions. Thus the manufacturers need to adapt their manufacturing process according to the raw material used in order to decrease variability in the final product.

During the manufacturing process, gelatin is submitted to $\mathrm{pH}$ and temperature variations that are known to change its structure (Digenis et al., 1994; Ofner, Zhang, Jobeck, \& Bowman, 2001; Schrieber \& Gareis, 2007; Yannas \& Tobolsky, 1967). As increase in temperature increases cross-link formation (Digenis et al., 1994), it can be assumed that the process may influence this reaction. Gelatin is a polycrystalline polymer whose structure consists of helical regions composed of triple or double helices and a coil structure, also called amorphous phase. The triple helices, considered as physical bonds (Yang et al., 2016), reduce the mobility of the gelatin chains and thus should impair cross-link formation. During manufacturing, the drying step is particularly important because speed of drying influences gelatin structure (Dai, Chen, \& Liu, 2006). In order to gain a better understanding of the impact of gelatin manufacturing on cross-link formation and on its dissolution in water, it is necessary to preserve the physical state of the gelatin, and avoid any sample transformations such as solubilization. Near infrared and fluorescence spectroscopy can be used to study raw gelatin, i.e. in its commercial form, with no prior sample solubilization. These two techniques have already been used to study the structure, composition and physico-chemical properties of gelatins (Hashim et al., 2010; Liu, Yao, Wang, \& Li, 2000; Segtnan, Kvaal, Rukke, Schuller, \& Isaksson, 2003; Segtnan \& Isaksson, 2004). Segtnan et al. (2003) found that near infrared spectroscopy (NIRS) combined with a partial least square (PLS) regression could accurately predict the bloom, viscosity and moisture content of gelatin gels and dried gelatins, with a better prediction for the latter form.

Here we studied three production sites: A, B and C. The objective was to determine and explain the impact of production origin on the chemical composition and dissolution rate in water of fresh and aged pig skin gelatins and to suggest tools to predict the dissolution quality of gelatins. NIR and fluorescence spectroscopy combined with data processing were used to identify the key chemical functions involved in the possible changes.

\section{Materials and methods}

\subsection{Gelatin processing}

Pig skin gelatin batches from the three different production sites $A, B$ and $C$ were obtained from the same supplier. Sites A and C were located in EU countries (France and Belgium respectively) and site $B$ was located in the USA. Irrespective of production site, pig skins were immersed in a sulfuric acid bath $(\mathrm{pH}=1.3)$ at $18^{\circ} \mathrm{C}$ for $8 \mathrm{~h}$. The skins were washed in water and the gelatin extracted in a hot water bath. The gelatin was filtered, deionized, sterilized, dried and granulated. The main differences between the three processes are given in Table 1.

The final moisture content of the gelatins was around $12 \%$ for all three sites.

\subsection{Dissolution level determination}

The dissolution rate of gelatin was determined in six repeats per sample after the aging step following the USP convention, apparatus 2 (United States Pharmacopeial Convention, 2012). Gelatin films were prepared and aged for 4 weeks in a climatic chamber at $50{ }^{\circ} \mathrm{C} \pm 2{ }^{\circ} \mathrm{C}$ and $80 \% \pm 5 \%$ of relative humidity (RH). They were introduced in sinkers and immersed in the tanks of apparatus 2 described in the USP convention. The tanks contained deionized water at $37{ }^{\circ} \mathrm{C}$ stirred with paddles at $50 \mathrm{rpm}$. The absorbance at $218 \mathrm{~nm}$ of the dissolution medium was measured at $0,3,6,9,12$ and $15 \mathrm{~min}$. The dissolution rate was considered as corresponding to "compliant gelatin" when at least $50 \%$ of the gelatin had dissolved at $9 \mathrm{~min}$. Otherwise, the dissolution rate was considered as indicating "non-compliant gelatin".

\subsection{NIR spectroscopy analysis}

Analysis was performed on all the samples in granule form provided by the company, i. e. 10 samples from A, 44 samples from $B$ and 13 samples from C. In total 67 gelatin samples with "compliant" and "non-compliant" dissolution rates, before and after aging, in five repeats, using a Foss NIRSystems model 6500 scanning visible/NIR spectrometer (Foss NIRSystems, Silver Spring, MD, USA) under ISIscan software version 2.21 (Infrasoft International, Port Matilda, PA, USA). The aging conditions of the granules were the same than those previously described: 4 weeks in a climatic chamber (Sanyo, 294L, Osaka, Japan) at $50{ }^{\circ} \mathrm{C} \pm 2{ }^{\circ} \mathrm{C}$ and $80 \%$ $\pm 5 \%$ of relative humidity ( $\mathrm{RH})$.

Approximately $3 \mathrm{~g}$ of gelatin granules was placed in a $38 \mathrm{~mm}$ internal diameter ring cup. Five ring cups were prepared for each of the 134 samples. The ring cups were scanned in reflectance mode at $2 \mathrm{~nm}$ intervals from $400 \mathrm{~nm}$ to $2500 \mathrm{~nm}$, and 16 scans per cup were applied with a beam width of approximately $1 \mathrm{~cm}$ using an automatic sampler. The ring cups were rotated during the scanning so that the whole surface of the sample was analyzed, and the mean spectrum was recorded.

\subsection{Fluorescence spectroscopy analysis}

Fluorescence spectroscopy was carried out on a subsample owing to acquisition time. A total of 30 non-aged and 30 aged samples $(n=60)$ were analyzed using a spectrofluorometer in the range 200-750 nm (JASCO model FP-8300, Tokyo, Japan). To reduce variability of the analysis due to granule size, all the granules were crushed into a fine powder. The grinding was done in liquid nitrogen to prevent overheating due to friction. Approximately $300 \mathrm{mg}$ of each powdered gelatin sample was placed in a quartz cup and introduced into the spectrofluorometer. 3D spectra identified two relevant excitation/emission wavelengths; 280/305 nm and $355 / 420 \mathrm{~nm}$. Each of the 60 samples was analyzed in triplicate using these two excitation wavelengths (280 $\mathrm{nm}$ and $355 \mathrm{~nm}$ ). Emission spectra were acquired from $290 \mathrm{~nm}$ to $750 \mathrm{~nm}$ for the $280 \mathrm{~nm}$ excitation wavelength and from $365 \mathrm{~nm}$ to $750 \mathrm{~nm}$ for the $355 \mathrm{~nm}$ excitation wavelength. The excitation and emission slit widths were both set at $5 \mathrm{~nm}$.

\subsection{Spectra treatments and statistical analysis}

The spectra obtained from the NIRS were plotted in $\log (1 / R)$ with $R$ the reflectance and an extended multiplicative signal correction (EMSC) was applied under the Unscrambler software (v9.8, Camo Software AS, Norway). A linear baseline correction and normalization was applied to the fluorescence spectra under the same software. The water region was kept in this study because the 
Table 1

Processes conditions of the three production sites showing differences.

\begin{tabular}{|c|c|c|c|c|}
\hline & Site & A & B & $\mathrm{C}$ \\
\hline \multirow[t]{3}{*}{ Process steps showing differences } & Extraction water temperature & $53{ }^{\circ} \mathrm{C}$ & $57{ }^{\circ} \mathrm{C}$ & $53{ }^{\circ} \mathrm{C}$ \\
\hline & Deionization & ++ & + & ++ \\
\hline & Drying temperature range & $40-60{ }^{\circ} \mathrm{C}$ & $30-68{ }^{\circ} \mathrm{C}$ & $40-60{ }^{\circ} \mathrm{C}$ \\
\hline
\end{tabular}

binding degree of water may provide information on the gelatin dissolution and the NIRS allows analyzing it (Du Toit, 2009; Duconseille et al., 2016). Moreover, the moisture content (12\%) of the samples was low enough to avoid any overriding of the water signal on the other components signals.

Partial least squares discriminant analysis (PLS-DA) and principal component analysis (PCA) were performed on the categorical variables (sites A, B and C, compliant and non-compliant for both the aged and non-aged gelatins).

The production sites A and B provided gelatins with both compliant and non-compliant dissolution levels whereas the production site $C$ provided only compliant gelatins. To obtain a balanced statistical plan, the PCA had to be performed on approximately the same number of "compliant" and "non-compliant" dissolutions. For this reason, only the dissolution of the A and B sites was studied.

The PCA loadings exhibit the wavelengths that contribute to the highest variation described by the principal components (PC). The peaks on PCA loadings (positive and negative) indicate wavelengths that contribute most to the difference between the gelatins of the three origins of production (Dupont, 2002). The most discriminative wavelengths identified on the loadings were associated with molecular functions (NIRS) or fluorophores (Fluorescence) by comparison with the scientific literature (Kato, Nishikawa, \& Kawakishi, 1995; Liu et al., 2000; Murray, 1993). NIRS reflectance and fluorescence intensities corresponding to the wavelengths identified on the loadings as most discriminating were analyzed by ANOVA with a Tukey test using the STATISTICA software (v12, Statsoft Inc, Tulsa, USA).

\section{Results}

\subsection{PLS-DA results according to production origin}

Whatever the aging state, all the gelatins from the three sites, analyzed with NIRS data following a PLS-DA, showed that almost $100 \%$ of the samples were classified in their respective production site (Table 2). The PLS-DA from the fluorescence data could classify in their respective production sites more than $77 \%$ of the gelatins. An excitation at $280 \mathrm{~nm}$ was more efficient (92.3\% correct classification) than an excitation at $355 \mathrm{~nm}$ (87.8\% correct classification) (Table 2). Examples of PLS-DA figures are given in supplementary data. The interpretation of the results is the same than the one deduced from PCA.

Table 2

PLS-DA results of gelatins in each categorical variable (sites A, B and C).

\begin{tabular}{|c|c|c|c|c|c|c|}
\hline \multirow[t]{4}{*}{ Site } & \multicolumn{6}{|c|}{ Percentage of correct classification } \\
\hline & \multicolumn{3}{|c|}{ Before aging } & \multicolumn{3}{|c|}{ After aging } \\
\hline & \multirow[t]{2}{*}{ NIR } & \multicolumn{2}{|l|}{ Fluorescence } & \multirow[t]{2}{*}{ NIR } & \multicolumn{2}{|l|}{ Fluorescence } \\
\hline & & $\lambda_{e x}=280 \mathrm{~nm}$ & $\lambda_{e x}=355 \mathrm{~nm}$ & & $\lambda_{e x}=280 \mathrm{~nm}$ & $\lambda_{e x}=355 \mathrm{~nm}$ \\
\hline A & 100 & 90 & 87 & 97 & 77 & 77 \\
\hline B & 100 & 97 & 93 & 100 & 100 & 90 \\
\hline C & 100 & 93 & 90 & 99 & 97 & 90 \\
\hline
\end{tabular}

\subsection{PCA of NIR and fluorescence spectral response}

Most of the multivariate analysis on NIR and fluorescence spectral responses showed three clusters depending on the production site (Figs. 1-4).

\subsubsection{Before aging}

The production sites of the non-aged gelatins were separated by NIR spectroscopy on PC2. The chemical functions corresponding to the discriminant wavelengths highlighted by the loadings were identified according to Murray (1993) (Fig. 1).

Except at $1646 \mathrm{~nm}$, the ANOVA on the wavelengths evidenced by the PCA loadings highlighted NIR absorbance significant differences regarding the three production sites $(p<0.05)$.

The B-gelatins localized on the positive part of PC2 (Fig. 1, b) had a higher content of chemical functions corresponding to the positive peaks of the PC2 loadings (Fig. 1, c) localized at 1912, 2070, 2132, 2224, 2330 and $2408 \mathrm{~nm}$. Also, the C-gelatins, in the negative part of PC2, had a higher content of chemical functions corresponding to the negative peaks of the PC2 loadings localized at $1014,1190,1396,1646$ and $1852 \mathrm{~nm}$. For instance, the positive peak at $1912 \mathrm{~nm}$ (Fig. 1, c) shows that the B-gelatins were characterized by a higher content of $\mathrm{H}_{2} \mathrm{O}$ and $\mathrm{RCOOH}$ functions. As the NIRS spectrum is composed of three overtones of each chemical function, it turns out that $\mathrm{H}_{2} \mathrm{O}$ also corresponds to a negative peak at $1396 \mathrm{~nm}$ attributed to $\mathrm{C}$-gelatins. It is difficult to assign $\mathrm{H}_{2} \mathrm{O}$ as more representative of $\mathrm{B}$ or C-gelatins. Thus $\mathrm{H}_{2} \mathrm{O}$ was not retained as a chemical function providing relevant information. Using this approach, the chemical functions potentially discriminant of the three production sites were identified (Table 3 ).

$\mathrm{B}$ and C-gelatins were significantly different on all the discriminative wavelengths, whereas A-gelatins were most often not different from B and C-gelatins $(p<0.05)$. NIR spectra interpretation suggests that $\mathrm{C}$-gelatins had more $\mathrm{CH}, \mathrm{CH}_{2}$ and $\mathrm{CH}_{3}$ functions than $\mathrm{A}$ and $\mathrm{B}$ gelatins. C-gelatins also showed more absorbance at $1396 \mathrm{~nm}$, which can be attributed either to ${ }^{\circ} \mathrm{CH}_{3}$ and ${ }^{\circ} \mathrm{CH}_{2}$ radical functions, or to arOH or $\mathrm{H}_{2} \mathrm{O}$. C-gelatins showed also more $\mathrm{OH}$ functions in aromatic groups than B-gelatins. B-gelatins had more functions with $\mathrm{C}=\mathrm{O}$ stretch and carboxyl $(\mathrm{RCOOH})$ functions than C-gelatins. B-gelatins also had more amide $\left(\mathrm{CONH}_{2} \mathrm{R}\right)$ and alcohol functions ( $\mathrm{ROH})$ than $\mathrm{A}$ and $\mathrm{C}$-gelatins respectively.

The fluorescence spectroscopy results revealed variations according to production site (Fig. 2). At $\lambda_{\mathrm{ex}}=280 \mathrm{~nm}$, production sites were separated on PC2 (Fig. 2, c). The B-gelatins were located in the negative part of the PCA score plot while A and C-gelatins were located in the positive part. . ANOVA performed on the wavelengths identified by the loadings showed the emission fluorescence at $\lambda_{\mathrm{em}}=305 \mathrm{~nm}$ (assigned to tyrosine; Lakowicz, 2006) to be stronger for A and B gelatins than for C gelatins $(p<0.01)$. At $335 \mathrm{~nm}$, the $C$ gelatins fluoresced more than the other two. The $B$ gelatins showed more fluorescence than the A and C gelatins at $394 \mathrm{~nm}(p<0.01)$. This wavelength corresponds to the emission peak of dityrosine close to $400 \mathrm{~nm}$ (Liu et al., 2000, Duconseille et al., 2016). The fluorescence intensity at $292 \mathrm{~nm}$ did not show any significant difference by production site $(p>0.1)$.

After an excitation at $\lambda_{\mathrm{ex}}=355 \mathrm{~nm}$, the PCA on emission 

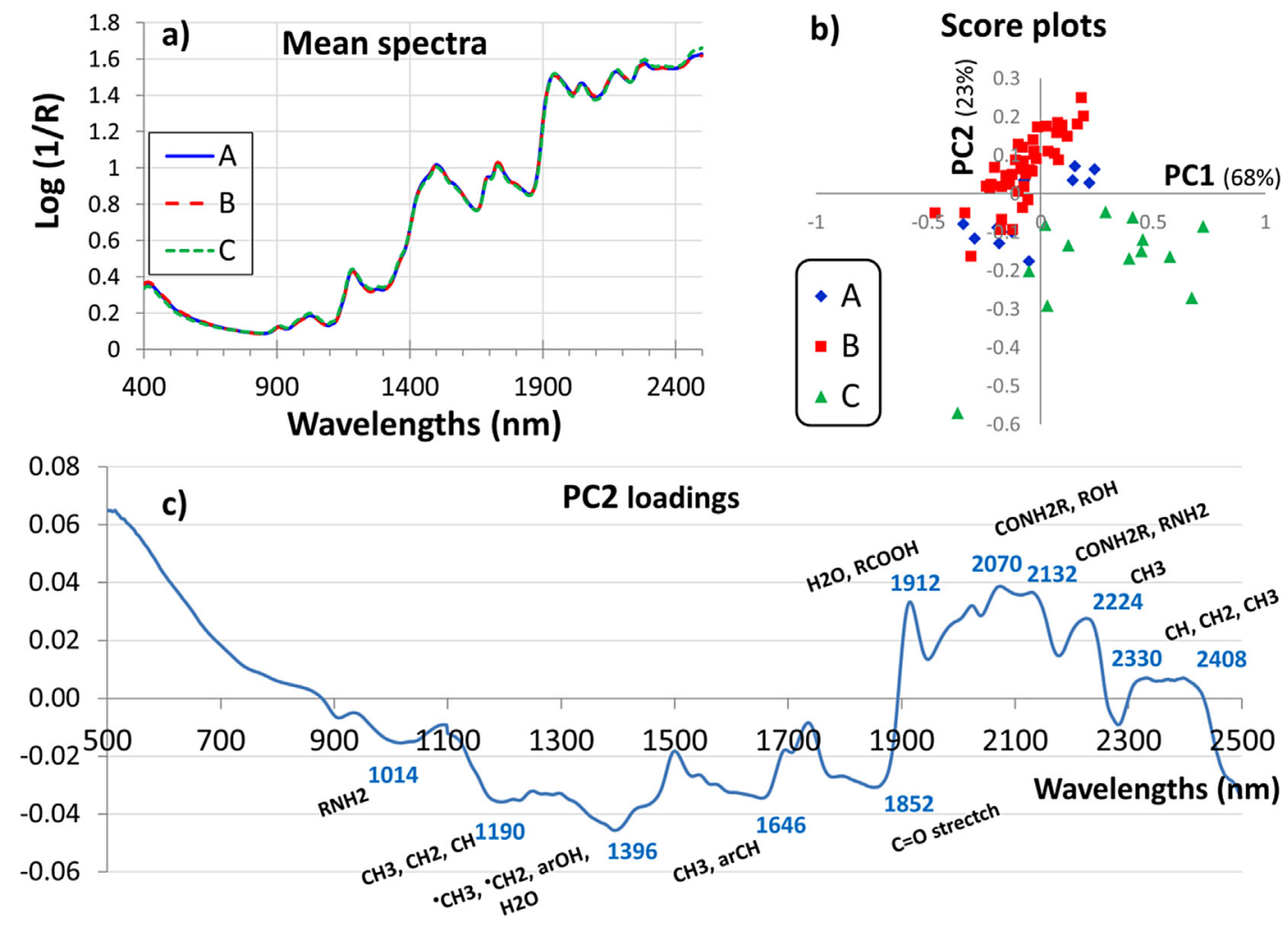

Fig. 1. PCA results of non-aged gelatin NIR spectra by production site.
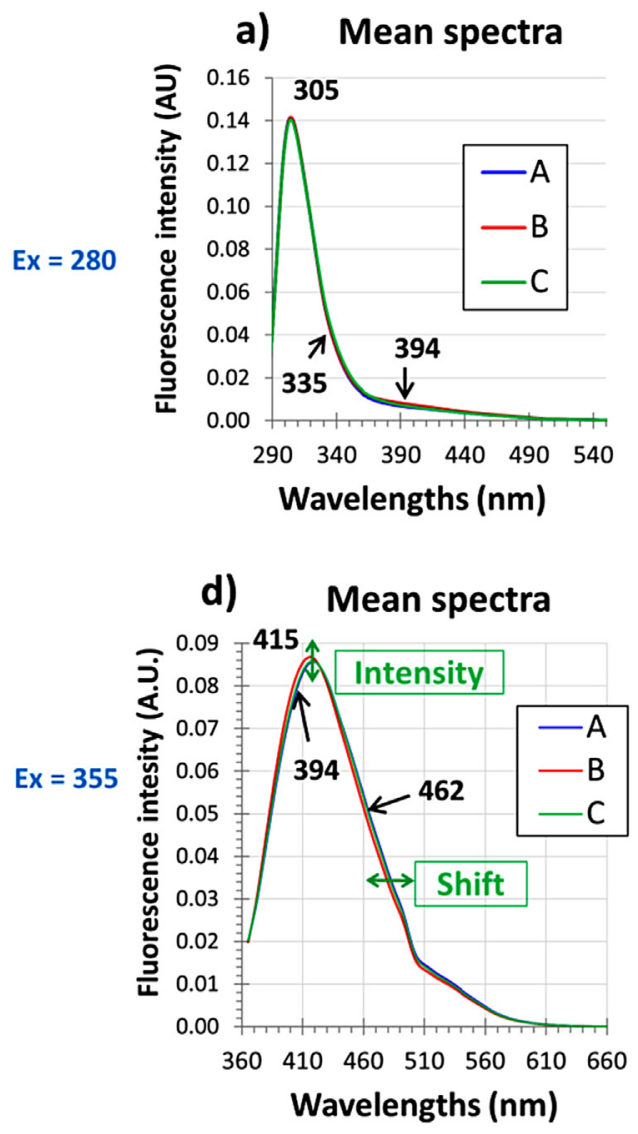

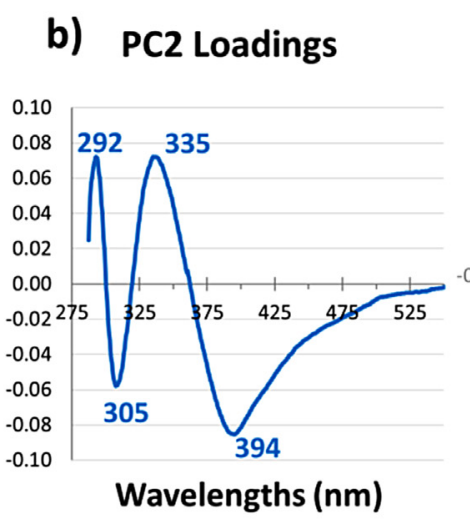

c) Score plots

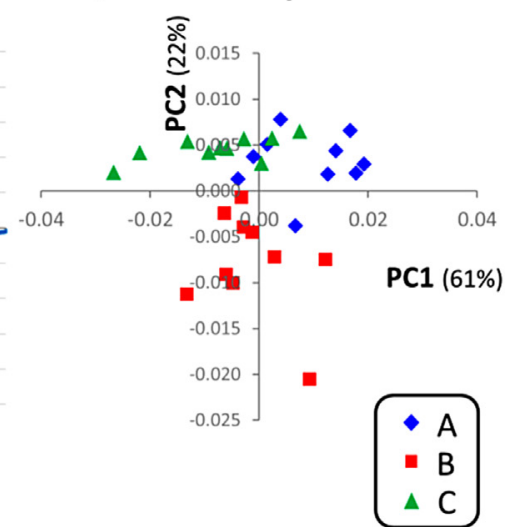

e) PC1 Loadings

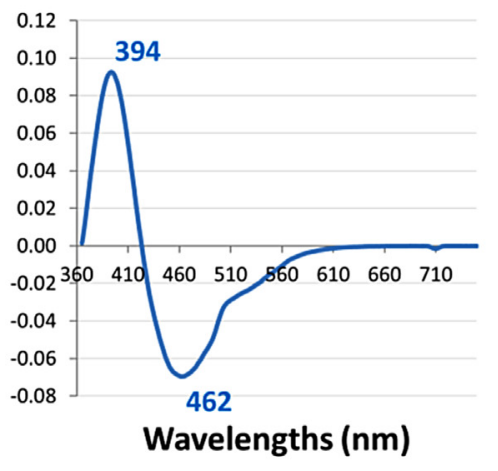

f) Score plots

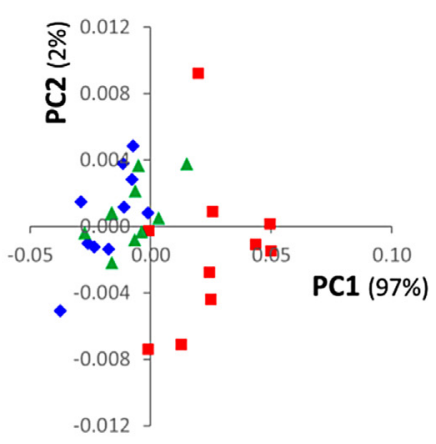

Fig. 2. PCA results of non-aged gelatin fluorescence spectra by production site. 

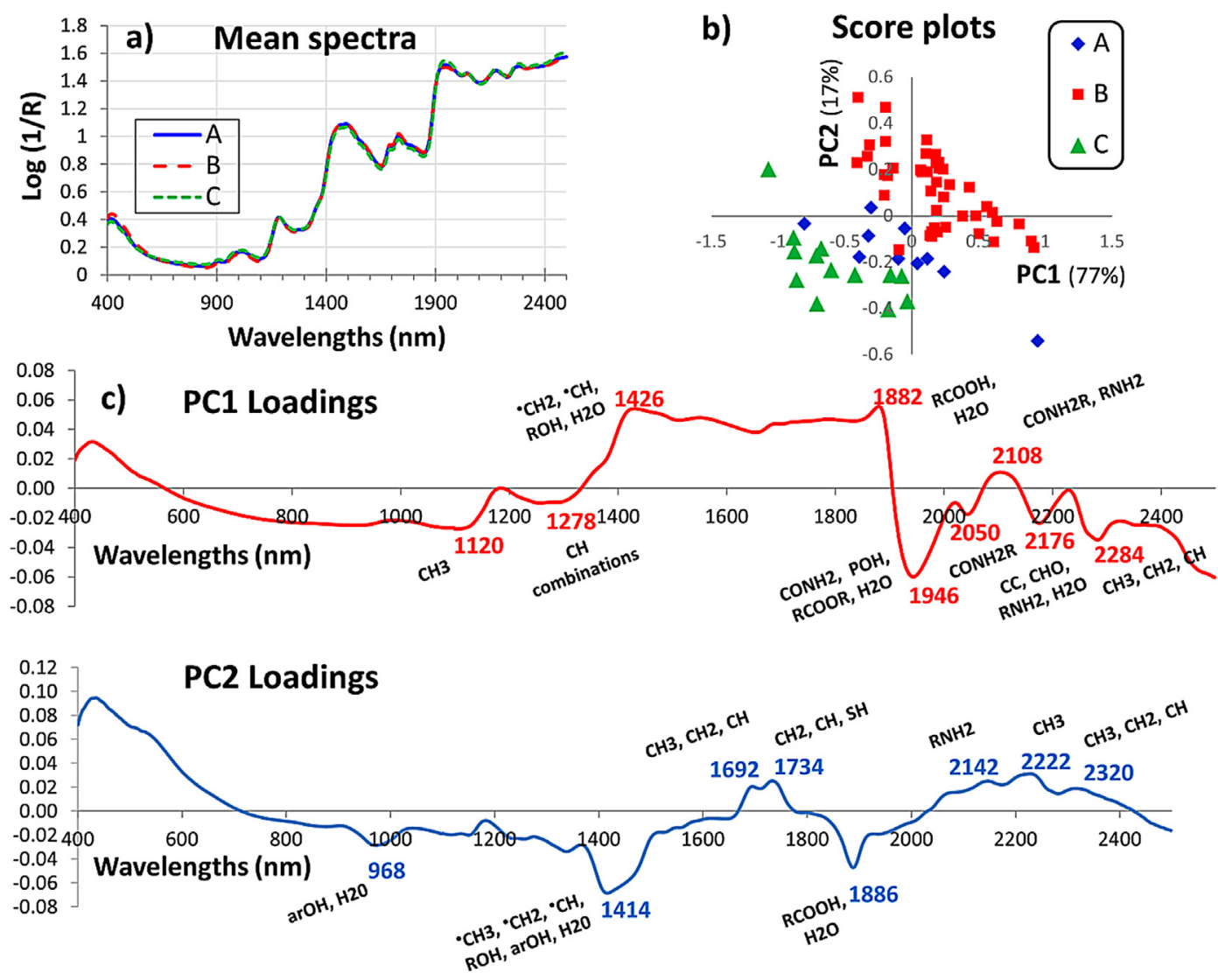

Fig. 3. PCA results of aged gelatin NIR spectra by production site.

fluorescence separated the production sites on PC1 (Fig. 2, f): Bgelatins on the positive part of the PC1 were isolated from A and Cgelatins located in the negative part of the PC1. The B-gelatins had a higher intensity of fluorescence at $394 \mathrm{~nm}$ (previously assigned to dityrosine) than A and C-gelatins, which fluoresced more at $462 \mathrm{~nm}$ than the B-gelatins $(p<0.001)$ (Fig. 2, e). These two discriminant wavelengths revealed by the loadings reflect a shift in the emission fluorescence peak which was initially at $415 \mathrm{~nm}$, assigned to 3,4dihydroxyphenylalanine (DOPA) in a previous study (Duconseille et al., 2016) (Fig. 2, d). Table 4 sums up these observations.

\subsubsection{After aging}

The PCA (Fig. 3) shows that NIRS allowed separating the gelatins from the 3 different production sites mostly on the PC2 and in a lesser extent on PC1. B-gelatins are mostly located in the positive parts of PC1 and PC2 score plots while A and C-gelatin are in the negative parts of PC1 and PC2 score plot. The separation of B-gelatins from $\mathrm{A}$ and $\mathrm{C}$-gelatin is clear, but the separation of $\mathrm{A}$ gelatin from C-gelatin is less evident. ANOVA performed on the absorbance corresponding to PC1 and PC2 loadings peaks revealed significant differences between the three production sites. The absorbance at $1414 \mathrm{~nm}$ (evidenced on PC2 loadings) was the only one that did not allow separating them significantly $(\mathrm{p}>0.05)$. The corresponding chemical functions were identified using the same previous approach as for the non-aged gelatins, as reported in Table 5.

The PCA results of fluorescence spectroscopy shown in Fig. 4 $(\mathrm{a}-\mathrm{f})$ revealed variations related to the production site. $\mathrm{B}$ and $\mathrm{C}-$ gelatins were located in the positive and negative part of the PC1 respectively while A-gelatins were in between after a $280 \mathrm{~nm}$ excitation.

Following $355 \mathrm{~nm}$ excitation, the PC1/PC2 score plot did not separate any groups while the PC1/PC3 allows the separation of samples related to production site on the PC3 (B gelatins in the negative part, $A$ and $C$-gelatins in the positive part of the PC3). The wavelengths that contribute most to the separation are revealed by the PCA loadings (Fig. 4, b and e). Looking at the PCA loadings, the A and C-gelatins showed a higher intensity fluorescence at $330 \mathrm{~nm}$ than the B-gelatins $\left(\lambda_{\mathrm{ex}}=280 \mathrm{~nm}\right.$ ). This wavelength does not correspond to the maximum emission peak, which is located at $303 \mathrm{~nm}$ (assigned to tyrosine) (Fig. 4, a). The peak at $408 \mathrm{~nm}$ corresponding to dityrosine is more characteristic of the B-gelatins (Fig. 4, a and b) $(p<0.05)$. At $\lambda_{\mathrm{ex}}=355 \mathrm{~nm}$, an emission peak at $420 \mathrm{~nm}$, corresponding to DOPA (Duconseille et al., Unpublished results), with shoulders at 494 and $535 \mathrm{~nm}$ is observed. The three production sites were separated on PC3. The loadings revealed five discriminative wavelengths (374, 403, 449, 494 and $535 \mathrm{~nm}$ ). The Bgelatins showed significantly more fluorescence intensity at $403 \mathrm{~nm}$ and less at $449 \mathrm{~nm}$ than the other two production sites $(p<0.05)$. The other wavelengths did not show any significant differences $(p>0.05)$. Table 6 sums up these observations.

\subsection{Dissolution rate discriminated by NIR and fluorescence spectroscopy}

In this study, production sites A and B provided both compliant and non-compliant gelatins, whereas production site $C$ provided only compliant gelatins. Only the dissolution of the A and B-gelatins was studied.

Before aging, the PCA performed on NIR spectra showed no separation of the dissolution rates. However, the PCA (PC1/PC3) on the fluorescence spectra discriminated the dissolution rates of $B-$ gelatins and not the A-gelatins at $\lambda_{\mathrm{ex}}=280 \mathrm{~nm}$ (Fig. 5). ANOVA 

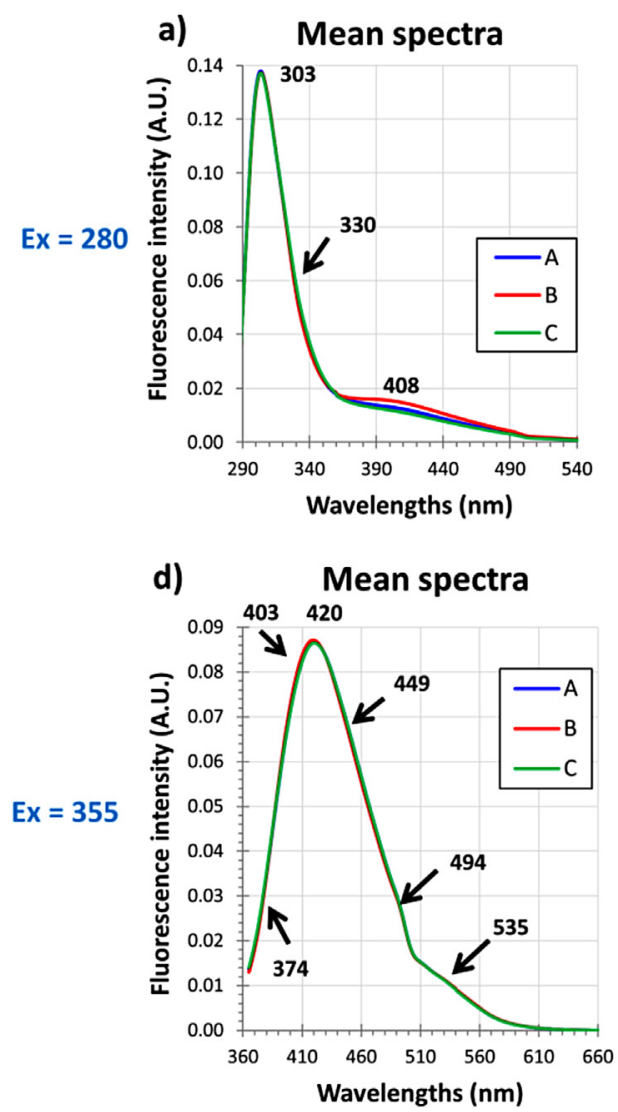
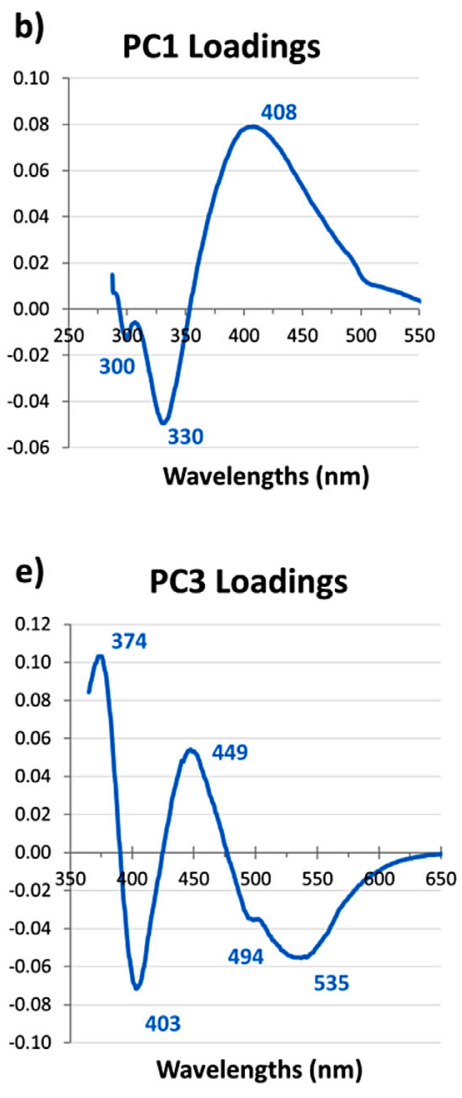

c)

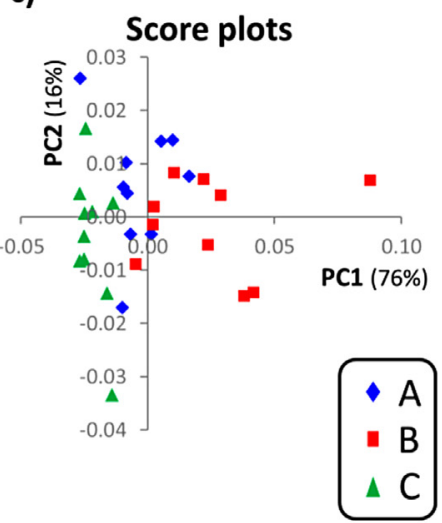

f) Score plots

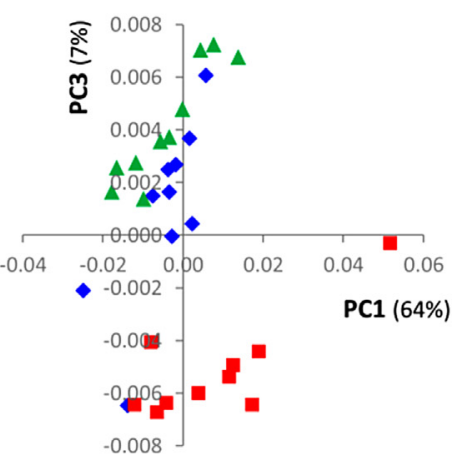

Fig. 4. PCA results of aged gelatins fluorescence spectra by production site.

Table 3

Chemical functions contributing to a separation by production sites in non-aged gelatins.

\begin{tabular}{ll}
\hline Functions & Proportions \\
\hline $\mathrm{CH}, \mathrm{CH}_{2}, \mathrm{CH}_{3}$ & $\mathrm{C}>\mathrm{A}=\mathrm{B}$ \\
$\cdot \mathrm{CH}_{3},{ }^{\circ} \mathrm{CH}_{2}$, arOH & $\mathrm{A}=\mathrm{C}>\mathrm{B}$ \\
$\mathrm{C}=\mathrm{O}$ stretch, $\mathrm{RCOOH}$ & $\mathrm{A}=\mathrm{B}>\mathrm{C}$ \\
$\mathrm{CONH}$ & $\mathrm{R}, \mathrm{ROH}$ \\
\hline
\end{tabular}

Table 4

Fluorophores identified as possibly discriminant for gelatins from the three production sites A, B and C.

\begin{tabular}{ll}
\hline Fluorophores & Proportions \\
\hline Tyrosine $(305 \mathrm{~nm})$ & $\mathrm{A}=\mathrm{B}>\mathrm{C}$ \\
Dityrosine $(394 \mathrm{~nm})$ & $\mathrm{B}>\mathrm{C}>\mathrm{A}$ \\
DOPA $(415 \mathrm{~nm})$ & $\mathrm{B}>\mathrm{A}=\mathrm{C}$ \\
\hline
\end{tabular}

Table 5

Chemical functions contributing to separation of the gelatins by production site.

\begin{tabular}{ll}
\hline Functions & Proportions \\
\hline arOH, $\mathrm{H}_{2} \mathrm{O}, \mathrm{CONH}{ }_{2}, \mathrm{POH}, \mathrm{RCOOR}$ & $\mathrm{C}>\mathrm{A}>\mathrm{B}$ \\
$\mathrm{CC}, \mathrm{CHO}, \mathrm{H}_{2} \mathrm{O}$ & $\mathrm{C}>\mathrm{B} ; \mathrm{A}=\mathrm{B} ; \mathrm{A}=\mathrm{C}$ \\
$\mathrm{SH}$ & $\mathrm{A}=\mathrm{B}>\mathrm{C}$ \\
$\mathrm{RCOOH}, \mathrm{ROH}, \cdot \mathrm{CH}_{2}, \cdot \mathrm{CH}$ & $\mathrm{B}>\mathrm{C} ; \mathrm{A}=\mathrm{B} ; \mathrm{A}=\mathrm{C}$ \\
\hline
\end{tabular}

performed from the PC1 and PC3 loadings revealed that the compliant gelatins tended to have higher intensity fluorescence at
Table 6

Fluorophores identified as discriminant for different production sites of gelatins.

\begin{tabular}{ll}
\hline Fluorophores & Proportions \\
\hline Tyrosine (280/303) & $\mathrm{A}>\mathrm{B}=\mathrm{C}$ \\
Dityrosine (280/408) & $\mathrm{B}>\mathrm{C}=\mathrm{A}$ \\
DOPA (355/420) & $\mathrm{B}>\mathrm{A}=\mathrm{C}$ \\
\hline
\end{tabular}

$344 \mathrm{~nm}$ than the non-compliant ones $(p=0.08)$. The other loadings presented no significant differences between the compliant and non-compliant gelatins.

After aging, the two groups of dissolution, i.e. compliant and non-compliant, were discriminated by PCA on both NIR and fluorescence spectra of both production sites A and B (Figs. 6 and 7). Fig. 6 gives the PCA results of the NIR spectra of aged gelatins. Compliant gelatins were located in the positive part of the PC1 and non-compliant ones on the negative part. When the production sites were analyzed separately, the dissolutions were also discriminated on PC1 and the same loadings were obtained (data not shown).

The loadings of PC1 revealed that the compliant gelatins exhibited higher absorbance intensity at 1424 and $1882 \mathrm{~nm}$, whereas the non-compliant gelatins showed higher absorbance intensity at 1942, 2180 and $2284 \mathrm{~nm}$ (Fig. 6). The ANOVA highlighted significant differences between the compliant and noncompliant gelatins $(p<0.01)$.

On A-gelatins, no separation was observed on the PC1/PC2 score plot analysis, but PC1/PC3 analysis separated compliant (positive part of PC3) from non-compliant gelatins (negative part of PC3) 


\section{Before aging $\quad \underline{B}$-site}
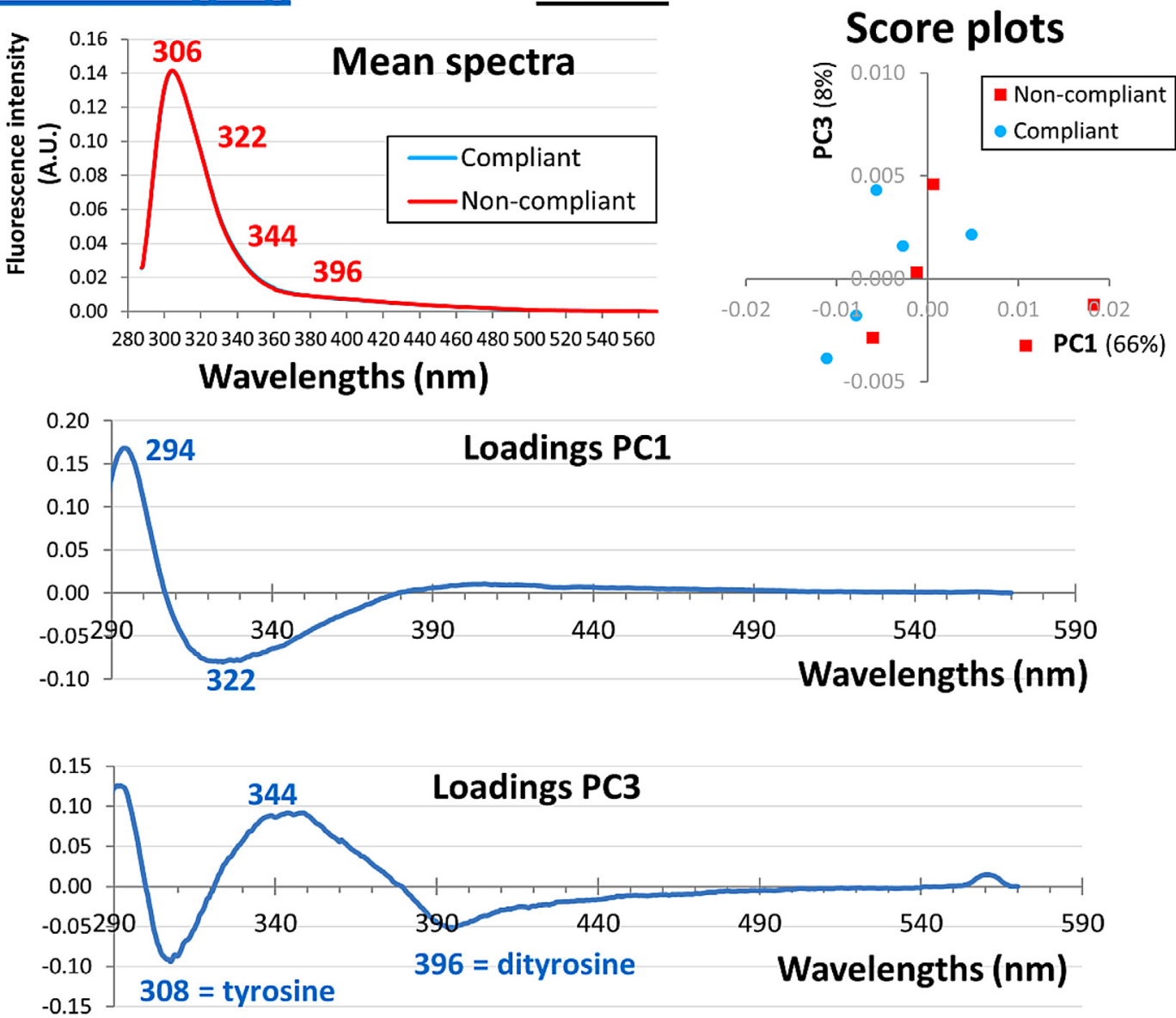

Fig. 5. PCA results of non-aged gelatin fluorescence spectra by dissolution rate category.

(Fig. 7). However, the ANOVA performed on the fluorescence intensities at the wavelengths identified on the loadings revealed no significant differences on comparing compliant and non-compliant gelatins $(p<0.05)$.

On the PCA score plot of B-gelatins, non-compliant and compliant samples were located in the positive and negative parts of the PC2 respectively. The dissolution rates of B-gelatins showed significant differences in emission fluorescence at 294 and $331 \mathrm{~nm}$ after excitation at $\lambda_{\mathrm{ex}}=280 \mathrm{~nm}(p<0.05)$. The non-compliant gelatins fluoresced at $294 \mathrm{~nm}$, and the compliant gelatins fluoresced more at $331 \mathrm{~nm}$.

At $\lambda_{\mathrm{ex}}=355 \mathrm{~nm}$, the aged compliant A-gelatins were separated from the aged non-compliant ones (Fig. 8) on PC1. The noncompliant ones are on the positive part of the PC1 and the compliant ones on the negative part. The PCA revealed wavelengths contributing to this separation, but the ANOVA showed no significant differences between the compliant and non-compliant gelatins $(p>0.05)$ at 377 and $429 \mathrm{~nm}$. However, the non-compliant gelatins tended to fluoresce more at $493 \mathrm{~nm}(p<0.07)$ and $528 \mathrm{~nm}(p<0.1)$ than the compliant ones.

\section{Discussion}

NIR and fluorescence spectroscopies discriminated the gelatins coming from the three production sites according to their spectral signatures, before and after aging.

The PLS-DA performed on the NIR and fluorescence spectra showed a classification rate of the gelatins superior to $77 \%$ whatever the aging state. However, the A gelatins were systematically less correctly classified. This is supported by the PCA results which showed that A gelatins were always located between the B and Cgelatins, and therefore less well separated.

Although NIR spectroscopy is generally used to characterize samples from their spectral signatures, spectral analysis also yields information on the chemical composition of samples.

It turns out that the chemical composition differed from one production site to another even when the raw material came from pig skin for the entire gelatin batches studied, and even when the gelatins were all pre-treated in fairly similar acid conditions.

\subsection{Impact of production origin on gelatin structure and composition before aging}

Before aging, the C-gelatins had more $\mathrm{CH}, \mathrm{CH}_{2}$ and $\mathrm{CH}_{3}$ functions, generally attributed to lipids, than $\mathrm{A}$ and B-gelatins. These lipids could be extracted at the same time as the collagen, and despite the mechanical removal and filtration step, it is possible that traces of lipids remained in the final product (Schrieber \& Gareis, 2007). The A and B-gelatins had more RCOOH functions than C-gelatins, which could be attributed either to acidic amino acids (glutamate or aspartate) or to the oxidation of the protein backbone in the presence of iron and oxidizing reagents such as hydrogen peroxide $\left(\mathrm{H}_{2} \mathrm{O}_{2}\right)$ (Berlett \& Stadtman, 1997). As hydrogen peroxide is added to bleach the gelatin, and iron is naturally present 


\section{After aging}
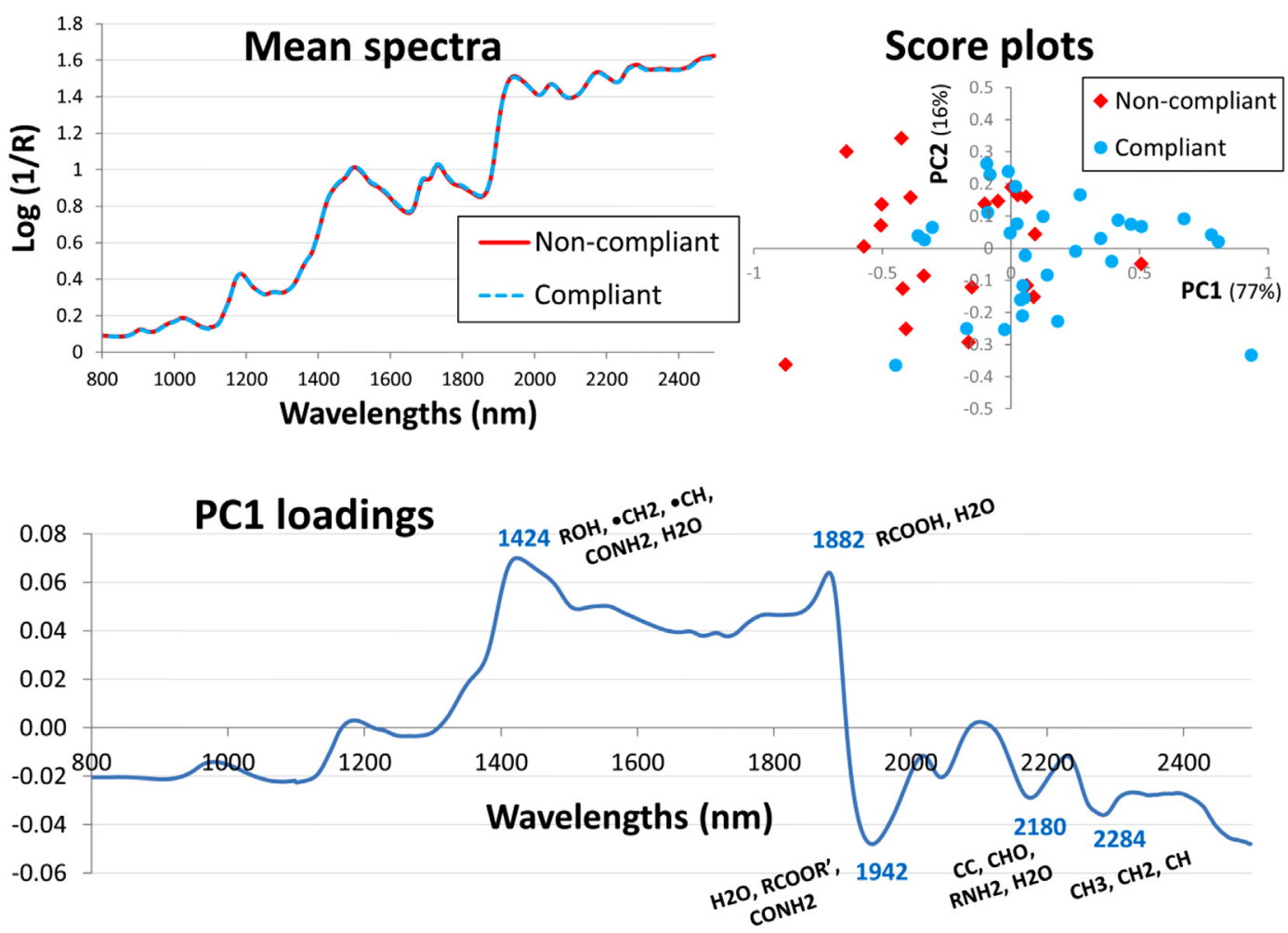

Fig. 6. PCA results of aged gelatin NIR spectra by dissolution rate category (sites A \& B).

in the water and in skin, they may induce oxidation reactions (Promeyrat, 2013). One plausible explanation for the greater abundance of $\mathrm{RCOOH}$ functions in A and B-gelatins could be the higher content of oxidizing agents. It is difficult to draw any firm conclusion.

In addition, the results highlighted different contents of tyrosine, dityrosine and DOPA in the gelatins from the three production sites. The wavelengths highlighted by the loadings after $355 \mathrm{~nm}$ excitation did not correspond to an emission peak on the mean spectra, but to a shift of the B-gelatin peak. Many factors such as the polarity of the fluorophore and its neighboring molecules, the structure of the fluorophore and the types of chemical interactions with its environment, impact the emission wavelength and therefore induce shifts (Lakowicz, 2006).

The solvent is the main factor studied influencing the emission wavelengths of the fluorophores (Lakowicz, 2006). For instance, the tryptophan emission can range from $308 \mathrm{~nm}$ to $355 \mathrm{~nm}$ and is correlated with the degree of solvent exposure (Vivian \& Callis, 2001). The moisture degree or the structural state of water of the studied gelatins could have modified the emission peak of such fluorophores excited at $355 \mathrm{~nm}$, and may be responsible for the shift observed.

To sum up, our results reveal a difference in B-gelatin structure or chemical composition compared with the gelatins from the other two production sites. These results show that type A pig skin gelatins differ by their chemical composition and/or apparently by their structure according to their production origin.

\subsection{Impact of the production origin on gelatin structure and composition after aging}

After aging, the gelatins from the three production sites were correctly separated by NIR spectroscopy, but the wavelengths allowing the discrimination differed from those observed before aging. This means that the aging step induced chemical modifications in the gelatins, and that these modifications were dependent on production origin.

Before aging, C-gelatins exhibited more absorbance at $1396 \mathrm{~nm}$ which is attributed either to radicals $\cdot \mathrm{CH}$ and ${ }^{-} \mathrm{CH}_{2}$ or to arOH or $\mathrm{H}_{2} \mathrm{O}$. However, since $\cdot \mathrm{CH}$ and ${ }^{\circ} \mathrm{CH}_{2}$ radicals are highly reactive and have very short lifetime (Davies \& Dean, 1997), it is unlikely that they could be detected.

Before aging, no difference in aldehydes ( $\mathrm{CHO}$ ) was observed between the production sites while, after aging, C-gelatins exhibited more aldehydes than B-gelatins. There was either an increase in aldehyde functions in C-gelatins with aging or a decrease in aldehyde functions in B-gelatins. There are two possible explanations: the oxidation of $\mathrm{C}$-gelatins increasing aldehydes with aging or the reaction of aldehydes of B-gelatins to form other compounds such as Schiff bases. Either possibility is plausible given that oxidation of amine functions into aldehyde functions can occur in gelatin on a lysine or arginine side-chain, and that cross-links between aldehyde and amine functions are formed in high temperature and humidity conditions (Digenis et al., 1994; Promeyrat, 2013).

The same three fluorophores, tyrosine, dityrosine and DOPA, were impacted by both production origin and aging. Before aging, $\mathrm{A}$ and B-gelatins showed the same levels of tyrosine fluorescence intensity, but after aging, A-gelatins had more tyrosine fluorescence than B-gelatins. Likewise, before aging, the fluorescence intensity attributed to dityrosine was greater in B-gelatins than in C and Agelatins. However, after aging, A and C-gelatins had the same dityrosine fluorescence intensity, though still less than the B-gelatins. These observations suggest that the decrease in tyrosine and the formation of dityrosine are not of the same magnitude during 

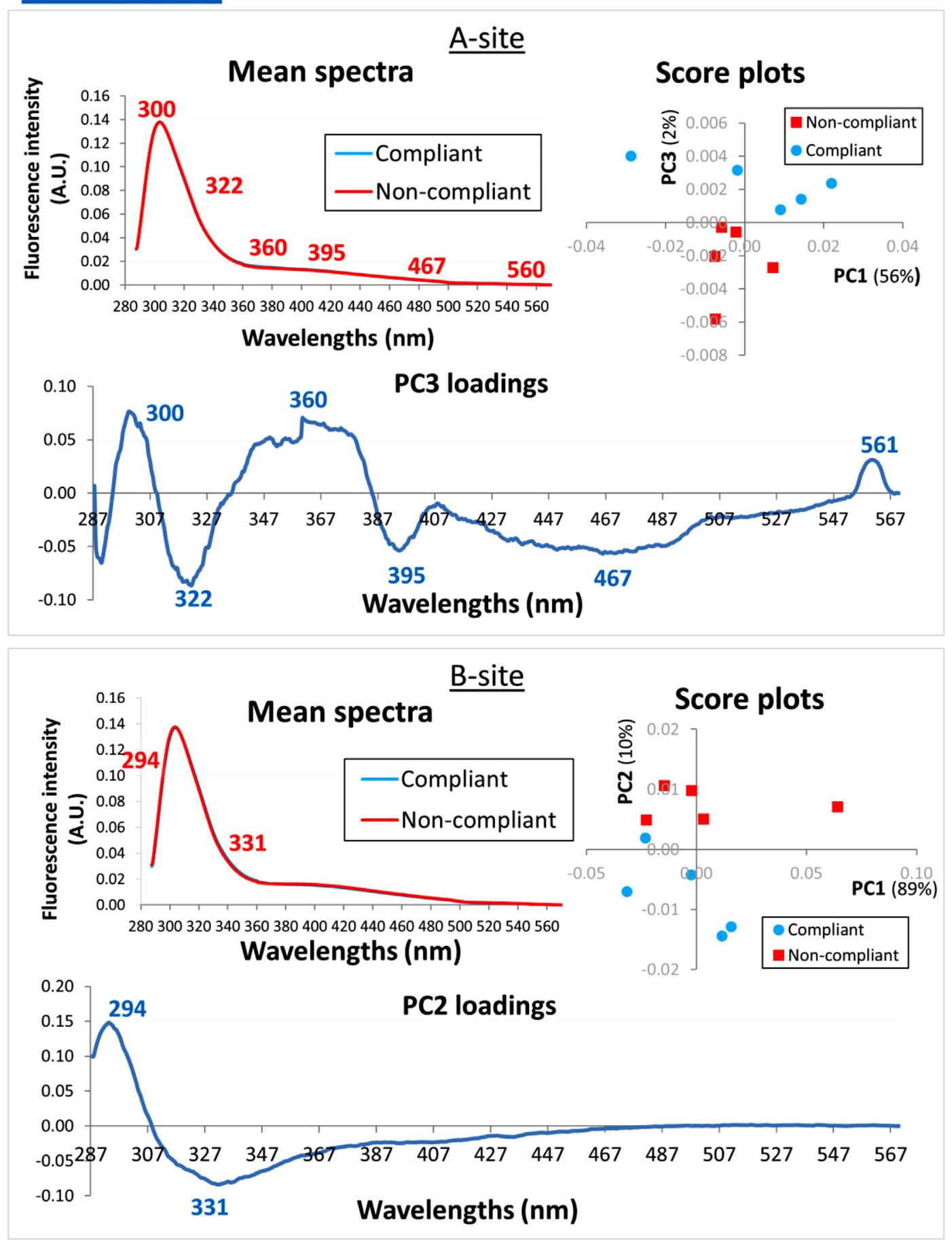

Fig. 7. PCA results of aged gelatin fluorescence spectra $\left(\lambda_{e x}=280\right)$ by dissolution rate category.

aging, according to production site. This justifies the hypothesis that there are structural differences between gelatins from the three production sites that impact the dityrosine formation by favoring or preventing the tyrosine encounter, i.e. the tyrosines of Agelatins react together less than the tyrosines of B-gelatins. The structural state of gelatin has been studied by Segtnan and Isaksson (2004), who attributed the $2160-2170 \mathrm{~nm}$ region to the single chains or the single helices, the band at $2180 \mathrm{~nm}$ to the triple helices and the band at $2208 \mathrm{~nm}$ to the triple helices or $\beta$-turn, which are the source of the nucleation of triple helix bundles, also called junction zones.

A and/or C-gelatins showed more reflectance at $2176 \mathrm{~nm}$ than Bgelatins. This wavelength was attributed to triple helices by Segtnan and Isaksson (2004). Thus A and/or C-gelatins should have more triple helices than B-gelatins. As triple helices are ordered structures, considered as physical bonds (Yang et al., 2016), they should reduce the mobility of gelatin chains. Thus if A-gelatins have more triple helices, then the tyrosine molecules in A-gelatins are 


\section{After aging $\quad \underline{\text { A-site }} \quad \lambda e x=355 \mathrm{~nm}$}
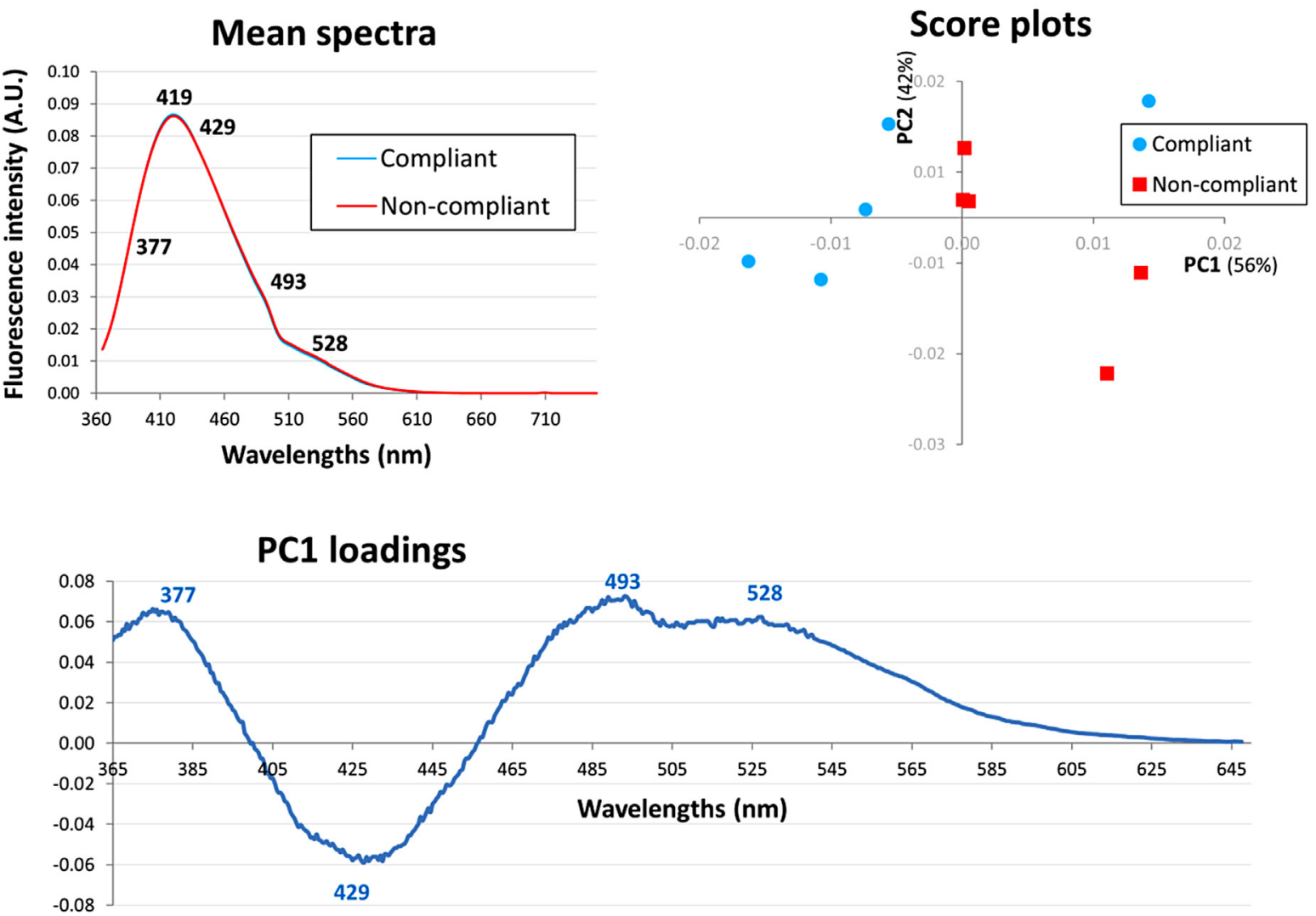

Fig. 8. PCA results of aged gelatins fluorescence spectra $\left(\lambda_{e x}=355\right)$ by dissolution rate category.

less likely to meet. To the best of our knowledge, there is no information on triple helix conformations that prevent or favor crosslink formation. However, numerous studies show that cross-links promote the formation of triple helices when they are found in small amounts in gelatin (Strauss \& Gibson, 2004; Watanabe, Tezuka, \& Ishii, 1997). By contrast, a large number of cross-links hinders triple helix formation and reduces the length of these triple helices, since cross-links stabilize the coil structure, preventing renaturation of the helices (Watanabe et al., 1997; Yang et al., 2016).

The structural differences between the gelatins according to their production origin impacted the fluorescence assigned to DOPA. After aging, B-gelatins showed a shift of this DOPA peak compared with the A and C-gelatins. Two shoulders on this peak at 494 and $535 \mathrm{~nm}$ may correspond to two other fluorophores not yet identified. Again, the shift observed reflects a structural or chemical difference in the environment of this fluorophore corresponding to DOPA (Lakowicz, 2006).

\subsection{Impact of production origin on gelatin dissolution linked to structure and composition}

The A and B-sites produced gelatins with dissolution variability after aging, while for the C-site dissolution rate was constant. Two groups of dissolution: compliant and non-compliant, were discriminated by PCA on NIR results of both production sites A and $\mathrm{B}$ (Fig. 5). When the production sites were analyzed separately, the dissolutions were also discriminated on PC1, and the same loadings were obtained (data not shown). The "compliant" gelatin dissolutions showed greater intensity at 1424 and $1882 \mathrm{~nm}$. These two peaks were attributed to water by Luck (1976). More specifically, the band at $1882 \mathrm{~nm}$ was attributed to free water, whereas the band at $1942 \mathrm{~nm}$ characterizing the non-compliant dissolutions is close to $1936 \mathrm{~nm}$, and was attributed to the bound water in an unfavored energy state (Luck, 1976; Du Toit, 2009; Zhou et al., 2003). Hence the gelatins with non-compliant dissolution rates had more bound water than the compliant ones, which had more free water. The non-compliant dissolutions also showed greater intensity of $\mathrm{CHO}$, $\mathrm{RNH}_{2}$, and more $\mathrm{CH}$ combinations $\left(\mathrm{CH}, \mathrm{CH}_{2}\right.$ and $\mathrm{CH}_{3}$ functions). The presence of aldehyde functions in non-compliant gelatins suggests a higher oxidation status in these gelatins than in the compliant ones. The $\mathrm{CH}$ combinations may be attributed to aliphatic chains of lipids. This suggests that the non-compliant gelatins contain more lipids. This result is in line with the literature indicating that traces of lipids can occur in gelatin, and that Schiff bases are formed in gelatin by Maillard reactions between amine and carbonyl functions (e.g. aldehyde functions supplied by lipids), which could reduce the solubility of the gelatin (Duconseille et al., 2015; Rbii, 2010; Schrieber \& Gareis, 2007).

The tyrosine peak of compliant dissolutions of B gelatins is shifted slightly rightward compared with the non-compliant dissolutions. Thus differences in the structural or chemical environment of tyrosine are probably involved in the dissolution variability of B-gelatins (Lakowicz, 2006). As this amino acid can form dityrosine cross-links and is subject to oxidation (Liu et al., 2000; Masutani, Kinoshita, Tanaka, Ellison, \& Yoza, 2014), this could explain why small changes in its environment may lead to dityrosine formation or tyrosine oxidation and affect the gelatin dissolution rate. 
The differences observed after PCA on dissolutions from A-gelatins were actually not significant $(p>0.05)$. The A and B-gelatins were analyzed separately because when analyzed together with PCA, no separation of the dissolution rates was possible.

At $\lambda_{\mathrm{ex}}=355 \mathrm{~nm}$, only the dissolutions from site A could be separated. The small number of samples (five per dissolution) limited ANOVA performance, and only a tendency $(p<0.08)$ of the "non-compliant" dissolutions to fluoresce more at $493 \mathrm{~nm}$ and $528 \mathrm{~nm}$ was observed. These wavelengths correspond to shoulders of the emission peak assigned to DOPA, and could be due to small peaks lost in the fluorescence of DOPA. The corresponding fluorophores are not identified.

Interestingly, we could distinguish non-compliant dissolutions from compliant ones in B-gelatins before aging with fluorescence spectroscopy. The ANOVA on the loadings revealed only a tendency of compliant dissolutions to fluoresce more at $344 \mathrm{~nm}$ than the non-compliant ones under a $280 \mathrm{~nm}$ excitation $(p=0.08)$. Again, the fact that it was only a tendency can be attributed to the small number of samples, which reduces the power of ANOVA. This $344 \mathrm{~nm}$ wavelength did not correspond to a fluorescence emission peak on the mean spectra. However, it may come from a small peak lost in the tyrosine peak. In the literature, the tryptophan is known to fluoresce in the range $308-355 \mathrm{~nm}$ depending to its structural environment (Vivian \& Callis, 2001) when excited at around 280-295 nm (Kollias, Zonios, \& Stamatas, 2002). However, the tryptophan is not present in collagen, but it can come from other proteins extracted at the same time as the collagen. All these observations after fluorescence spectroscopy show that the causes of the decrease in gelatin dissolution are not necessarily the same in all the production sites. As it was possible to distinguish the compliant dissolutions from the non-compliant ones before aging, the production origin and not only the aging step must have an impact on the dissolution rate. The small differences observed in the manufacturing process for the temperature range of the drying step, the temperature of extraction and the degree of demineralization may be responsible for the structural and chemical differences observed between the gelatins. However it is plausible that various amounts of oxidizing agents such as iron or hydrogen peroxide are also involved. The concentration of hydrogen peroxide was apparently the same in all the gelatin batches, so the amount of iron may be responsible for this difference in oxidation level. The gelatins were produced in the EU and USA, so the pig breed and rearing conditions were different, and may also play a role in the differences observed. These differences are not only variations in chemical and/or structural environment of tyrosine, but also other unidentified fluorophores. Another cause suspected of playing a role in the variability of dissolution is the water binding degree. This can be influenced by either the structure or the composition of gelatins. The manufacturing process differs in the A and B-sites, but the C-site has the same process as A, and showed only compliant dissolutions, unlike site $A$. Thus the manufacturing process variations cannot alone explain the differences observed in the dissolution rate. A combination of multiple factors seems to be responsible.

\section{Conclusion}

NIR and fluorescence spectroscopy can be applied directly on the raw material and both approaches allowed the separation of the production sites and the dissolutions. Small differences in raw material or in processes are likely to induce significant changes in chemical composition and cross-link formation such as dityrosine on both freshly produced and aged gelatins. After aging, more binding of water to the gelatin chains, presence of lipids and more oxidation level promote non-compliant gelatins. The fluorescence spectroscopy not only yielded indications about the causes of the non-compliant dissolutions, but also showed that these causes depended on production origin. Even before aging, non-compliant dissolutions showed a tendency to fluoresce more at $344 \mathrm{~nm}$ under $280 \mathrm{~nm}$ excitation but the fluorophores involved are not yet identified.

To advance further in the understanding of the mechanisms involved in the impact of production origin on the decreased dissolution rate, and because shifts in fluorescence peaks and the presence of three overtones on the NIR spectra hinder the interpretation of results, complementary techniques need to be implemented. For instance, differential scanning calorimetry and circular dichroism could help improve our understanding of the mechanisms underlying structural changes induced by production origin and linked to the dissolution rate of gelatins.

\section{Appendix A. Supplementary data}

Supplementary data related to this article can be found at http:// dx.doi.org/10.1016/j.foodhyd.2016.08.001.

\section{References}

Berlett, B. S., \& Stadtman, E. R. (1997). Protein oxidation in aging, disease, and oxidative stress. Journal of Biological Chemistry, 272(33), 20313-20316.

Dai, C. A., Chen, Y. F., \& Liu, M. W. (2006). Thermal properties measurements of renatured gelatin using conventional and temperature modulated differential scanning calorimetry. Journal of Applied Polymer Science, 99(4), 1795-1801.

Davies, M. J., \& Dean, R. T. (1997). Radical-mediated protein Oxidation: From chemistry to medicine. Oxford University Press.

Digenis, G. A., Gold, T. B., \& Shah, V. P. (1994). Cross-linking of gelatin capsules and its relevance to their in-vitro in-vivo performance. Journal of Pharmaceutical Sciences, 83(7), 915-921.

Du Toit, G. (2009). Near infrared hyperspectral imaging and chemometrics for exploration and classification of whole wheat kernels (Thesis). Stellenbosch University Stellenbosch. Retrieved from: http://hdl.handle.net/10019.1/2978.

Duconseille, A., Andueza, D., Picard, F., Santé-Lhoutellier, V., \& Astruc, T. (2016) Molecular changes in gelatin aging observed by NIR and fluorescence spectroscopy. Food Hydrocolloids, 61, 496-503.

Duconseille, A., Astruc, T., Quintana, N., Meersman, F., \& Sante-Lhoutellier, V. (2015). Gelatin structure and composition linked to hard capsule dissolution: A review. Food Hydrocolloids, 43, 360-376.

Hashim, D. M., Man, Y. B. C., Norakasha, R., Shuhaimi, M., Salmah, Y., \& Syahariza, Z. A. (2010). Potential use of Fourier transform infrared spectroscopy for differentiation of bovine and porcine gelatins. Food Chemistry, 118(3), $856-860$

Kato, Y. Nishikawa, T. \& Kawakishi, S. (1995). Formation of protein-bound 3,4 dihyroxyphenylalanine in collagen type-i and type-iv exposed to ultravioletlight. Photochemistry and Photobiology, 61(4), 367-372.

Kollias, N., Zonios, G., \& Stamatas, G. N. (2002). Fluorescence spectroscopy of skin. Vibrational Spectroscopy, 28(1), 17-23.

Lakowicz, J. R. (2006). Principles of fluorescence spectroscopy (3rd ed.). Boston, USA Springer.

Liu, W. G., Yao, K. D., Wang, G. C., \& Li, H. X. (2000). Intrinsic fluorescence investigation on the change in conformation of cross-linked gelatin gel during volume phase transition. Polymer, 41(20), 7589-7592.

Luck, W. A. (1976). Hydrogen bonds in liquid water. In P. Shuster, G. Zundel, \& C. Sandorty (Eds.), The hydrogen bond (pp. 1369-1423). Amsterdam: New Holland Publishing.

Masutani, E. M., Kinoshita, C. K., Tanaka, T. T., Ellison, A. K. D., \& Yoza, B. A. (2014) Increasing thermal stability of gelatin by UV-induced cross-linking with glucose. International Journal of Biomaterials, 2014, 9.

Murray, I. (1993). Forage analysis by near infra-red spectroscopy. In A. B. Davies R. D. Baker, S. A. Grant, \& A. S. Laidlaw (Eds.), Sward measurement handbook (2nd ed.). The British Grassland Society.

Ofner, C. M., Zhang, Y. E., Jobeck, V. C., \& Bowman, B. J. (2001). Crosslinking studies in gelatin capsules treated with formaldehyde and in capsules exposed to elevated temperature and humidity. Journal of Pharmaceutical Sciences, 90(1), 79-88.

Promeyrat, A. (2013). Analyse et modélisation des mécanismes à l'origine des modifications des protéines lors du chauffage du tissu musculaire. Available from: http://www.theses.fr/2013CLF22333.

Rbii, K. (2010). Formation d'agrégats de hauts poids moléculaires dans la gélatine et comportement en solution acqueuse (PhD). Université de Toulouse.

Schrieber, R., \& Gareis, H. (2007). Gelatin handbook - Theory and industrial practice. Wiley-VCH.

Segtnan, V. H., \& Isaksson, T. (2004). Temperature, sample and time dependent structural characteristics of gelatine gels studied by near infrared spectroscopy. 
Food Hydrocolloids, 18(1), 1-11.

Segtnan, V. H. Kvaal, K., Rukke, E. O., Schuller, R. B., \& Isaksson, T. (2003). Rapid assessment of physico-chemical properties of gelatine using near infrared spectroscopy. Food Hydrocolloids, 17(5), 585-592.

Strauss, G., \& Gibson, S. M. (2004). Plant phenolics as cross-linkers of gelatin gels and gelatin-based coacervates for use as food ingredients. Food Hydrocolloids, $18,81-89$.

United States Pharmacopeial Convention. (February 1, 2012). Chapter 711, revision bulletin, official. http://www.usp.org/sites/default/files/usp_pdf/EN/USPNF/ revisions/m99470-gc_711.pdf.

Vivian, J. T., \& Callis, P. R. (2001). Mechanisms of tryptophan fluorescence shifts in proteins. Biophysical Journal, 80(5), 2093-2109.
Watanabe, K., Tezuka, Y. . o, \& Ishii, T. (1997). Configuration between Re-Formed collagen triple helices and artificially introduced cross-links in gelatin gels. Macromolecules, 30(25), 7910-7913.

Yang, Z., Hemar, Y., Hilliou, L., Gilbert, E. P., McGillivray, D. J., Williams, M. A. K., et al. (2016). Nonlinear behavior of gelatin networks reveals a hierarchical structure. Biomacromolecules, 17(2), 590-600.

Yannas, I. V., \& Tobolsky, A. V. (1967). Cross-linking of gelatine by dehydration. Nature, 215(5100), 509-510.

Zhou, G. X., Ge, Z., Dorwart, J., Izzo, B., Kukura, J., Bicker, G., et al. (2003). Determination and differentiation of surface and bound water in drug substances by near infrared spectroscopy. Journal of Pharmaceutical Sciences, 92(5), 1058-1065. 